\title{
Effective Justice
}

\author{
Roger Crisp \\ St Anne's College, University of Oxford, Oxford, United Kingdom \\ roger.crisp@st-annes.ox.ac.uk
}

\author{
Theron Pummer \\ Department of Philosophy, University of St Andrews, St Andrews, \\ United Kingdom \\ tgp4@st-andrews.ac.uk
}

\begin{abstract}
Effective Altruism is a social movement which encourages people to do as much good as they can when helping others, given limited money, time, effort, and other resources. This paper first identifies a minimal philosophical view that underpins this movement, and then argues that there is an analogous minimal philosophical view which might underpin Effective Justice, a possible social movement that would encourage promoting justice most effectively, given limited resources. The latter minimal view reflects an insight about justice, and our non-diminishing moral reason to promote more of it, that surprisingly has gone largely unnoticed and undiscussed. The Effective Altruism movement has led many to reconsider how best to help others, but relatively little attention has been paid to the differences in degrees of cost-effectiveness of activities designed to decrease injustice. This paper therefore not only furthers philosophical understanding of justice, but has potentially major practical implications.
\end{abstract}

\section{Keywords}

effective justice - effective altruism - justice - benevolence - charity 


\section{Introduction}

Effective Altruism is a social movement which encourages people to do as much good as they can when helping others, for example when giving to charity. ${ }^{1}$ The movement was spurred by an appreciation of the substantial differences in cost-effectiveness between charities, that is, differences in the average amount of good done per dollar donated to charities. It has been claimed, for example, that $\$ 40,000$ can be used either to help one person (by training a guide dog) or instead to help over one thousand people to at least as great an extent each (by providing surgeries reversing the effects of trachoma). ${ }^{2}$ At least if other things were equal, Effective Altruists would encourage you to use your money to do the latter rather than the former, on the ground that this would do much more good. Similar remarks apply to donations of time and expenditures of effort. Their central recommendation is to use resources put to altruistic purposes, so as to do the most good with them, without violating any side constraints there might be. ${ }^{3}$

This paper will begin by outlining the normative constituents of the minimal philosophical view underpinning this central recommendation of Effective Altruism. We have aimed at finding a view that (1) is sufficient to justify the central Effective Altruist recommendation, (2) is independently philosophically plausible, and (3) is philosophically minimal, so as to fit with the widest range of respectable ethical traditions. We claim not that all Effective Altruists would accept this minimal view, but that many and perhaps most would. We also take our direct target to be the justification of Effective Altruism's central recommendation, rather than of the Effective Altruism movement or participation in it. The minimal view would justify the latter indirectly, given certain plausible assumptions. For all we argue here, these assumptions (plausible as they are) may fail to hold, and many activities characteristic of participation in the Effective Altruism movement - donating to certain charities and encouraging others to do likewise, publicly discussing how to do the most good with one's career, providing cost-effectiveness information to others, etc. - may in fact not be the best ways to help others. For example, Effective Altruists would recommend not sharing cost-effectiveness information with others if doing so counterproductively led people to decide in even less cost-effective ways than they otherwise would have done.

Once we have outlined the minimal view underpinning Effective Altruism, we will then turn to our main claim, that there is an analogous minimal

1 Singer 2015; MacAskill 2015.

2 Ord 2013.

3 See MacAskill 2019 on the definition of Effective Altruism. 
philosophical view which might underpin Effective Justice, a social movement that would encourage promoting justice most effectively, given limited resources. The latter minimal view reflects an insight about justice, and our nondiminishing reason to promote more of it, that surprisingly has gone largely unnoticed and undiscussed. The Effective Altruism movement has led many to reconsider how best to help others, but relatively little attention has been paid to the differences in degrees of cost-effectiveness of activities designed to decrease injustice or promote justice. This paper therefore has potentially major practical implications.

What, then, is the minimal philosophical view underpinning Effective Altruism? Clearly, Effective Altruism involves the combination of "altruism" with "effectiveness." We take it that benefiting others is the sense of "doing good" picked out by Effective Altruism, given the actual practices of Effective Altruists and given that benefiting others is what altruism concerns. ${ }^{4}$ Presumably, you have at least some reason to benefit at least certain other individuals, at least when other things are equal. ${ }^{5}$ According to what we call Impartial Altruism, you have a reason to benefit all others, regardless of factors like their gender, race, and so forth, and regardless of any special relations to you.

Turn now to effectiveness. According to Maximizing Altruism, among those others you have reason to benefit, you have more reason to benefit them more, and most reason to benefit them as much as possible, other things being equal. This view applies to beneficence at any level. For example, a parent choosing among various equally costly presents for her child has more reason, other things being equal, to choose those that benefit her child more, and most reason to choose one that benefits her child most. But clearly, for Effective Altruists, effectiveness does not end at home. They apply effectiveness to altruism in an impartial sense.

According to Impartial Altruism and Maximizing Altruism taken together, you have a reason to benefit all others, more reason to benefit them more, and most reason to benefit them as much as possible, other things being equal. We also need to add an assumption of practical relevance, according to which

4 Doing good in this sense is thus something that could be endorsed by skeptics of "the good, simpliciter" such as Foot (1983) and Thomson (2008).

5 This final phrase, which we shall henceforth tend to omit, is to allow for the possibility that certain considerations, such as a potential beneficiary's deserving to suffer, may cancel or "silence" the reason to benefit. 
the reason to benefit others impartially at least sometimes outweighs all other reasons, determining what there is most reason to do, all things considered. Since Impartial Altruism, Maximizing Altruism, and this assumption of practical relevance are together (1) sufficient to justify the central Effective Altruist recommendation, (2) independently philosophically plausible, and (3) philosophically minimal, we believe their conjunction provides the minimal philosophical view underpinning Effective Altruism. We do not hold that this view is so minimal that no one could object to it. A rational egoist, for example, may deny any other-regarding reasons, whether partial or impartial, while someone who accepts the possibility of impartial reasons of beneficence might maintain that they are in every case overridden by other, partial reasons. But we believe that many people, having properly grasped the view, would accept it.

The minimal nature of Effective Altruism's philosophical underpinning is important to observe in the context of contemporary debate, since several commentators have raised objections to Effective Altruism as if it implied consequentialism. ${ }^{6}$ It is true that many heavily involved in the Effective Altruism movement are consequentialists. But the combination of Impartial Altruism and Maximizing Altruism, along with the assumption of practical relevance, is clearly compatible with non-consequentialist moral options, moral constraints, rights, and agent-relative reasons. ${ }^{7}$ This minimal view can be seen as a version of the sort of principle of impartial beneficence accepted by nonconsequentialist pluralists such as W.D. Ross. ${ }^{8}$ In a Rossian spirit, we shall now suggest that there is a reason to promote justice as well as a reason to promote well-being.

\section{$3 \quad$ Effective Justice}

According to what we call Impartial Justice, you have a reason to promote justice which extends to all individuals, regardless of factors like their gender, race, and so forth, and regardless of any special relations to you. And according to Maximizing Justice, among those your reason to promote justice extends to,

6 For example, see Gray (2015), Tumber (2015), Krishna (2016) and Fraser (2017).

7 While seemingly allowing that Effective Altruism is not very demanding (allowing for moral options), MacAskill says that giving to less effective charities on the basis of special personal connections would be "arbitrary" and "unfair" (2015, pp. 24-5). Whether or not MacAskill is correct, it is important to note that the minimal philosophical view underpinning Effective Altruism is consistent with the view that these connections can provide a direct justification for engagement in suboptimal altruism.

8 Ross (1930/2002, pp. 17-21) and Ross (1939, p. 271). 
there is more reason to promote more justice, and most reason to promote as much justice as possible, other things being equal. We suggest that, just as the combination of Impartial Altruism with Maximizing Altruism, along with an assumption of practical relevance, provides the minimal philosophical underpinning for Effective Altruism, the combination of Impartial Justice with Maximizing Justice may serve to underpin Effective Justice, a social movement encouraging the maximally effective promotion of impartial justice, given limited resources.

Neither Impartial Justice nor Maximizing Justice implies that all justicebased reasons have the same status or significance. Plausibly, reasons to avoid committing injustice tend to yield rightly enforceable duties of justice to avoid so acting. Perhaps, while one has such a stringent duty of justice not to steal purses, one does not have a similarly stringent duty of justice to prevent others from stealing purses. Such agent-relativity need not be unique to justice. Perhaps, while it is morally important to be the one who actually saves a drowning child, it is not similarly important to allow others to help. Nevertheless, Effective Justice and its proposed underpinning presuppose that justice can be promoted, which may seem in itself quite odd. How, and in what sense, could justice appropriately be promoted?

As ordinarily understood, justice and injustice may be properties of acts, agents, institutions, societies, or states of affairs; in each case, (in)justice can vary in degree. Given this plurality of bearers of justice, and the plurality of relations in which an agent could stand to these bearers and to the justice they bear, there are many potential sources of reasons to promote justice. The following four examples serve to illustrate and differentiate at least some of them.

Your Unjust Acts. You can commit fewer and smaller injustices or instead commit more and larger injustices. Suppose, for example, that you could expropriate oil from two people each of whom has a weak claim to it, or instead expropriate oil from ten others each of whom has a strong claim to it. Or suppose, as another example, that you can break moderately serious promises to two people, or instead break very serious promises to ten others. All other things are equal (that is, overall benefits are tied whether you commit fewer and smaller injustices or instead commit more and larger injustices, everyone involved is a stranger to you, and so on). ${ }^{9}$

9 We appreciate that more and larger injustices tend in practice to go hand in hand with more and larger losses of well-being, but are here supposing your two alternatives are tied with respect to overall benefits. 
Another's Unjust Acts. Donald is credibly threatening to commit fewer and smaller injustices as well as more and larger injustices. (We trust the reader will have no difficulty filling in the relevant details for the sake of concreteness.) You can prevent Donald from committing fewer and smaller injustices or instead prevent him from committing more and larger injustices. All other things are equal.

Unjust Institutions. The institutions within a particular Western nation are credibly threatening to encourage further gender discrimination in promotion processes for top business executives as well as deny women any legal right to freedom of speech. You can prevent the occurrence of one but not both of these ways in which the nation's institutions would otherwise become less just. All other things are equal.

Unjust Distributions. The world contains many people who are very badly off, much worse off than others, through no fault or choice of their own. Making those who are very badly off better off would, we might suppose, make the world less unjust. Suppose you can benefit 1 billion people. Each would receive a significant, same-sized benefit. You have a choice between benefiting 1 billion of the world's worst-off people or instead 600 million of the world's second-worst-off people alongside 400 million of the world's second-best-off people. All other things are equal.

Consider first Your Unjust Acts. If you choose the less unjust course of action, to that extent you will promote justice. If there are any justice-based reasons, then there are reasons to promote justice as a property of one's own acts. ${ }^{10}$

The injustice in Another's Unjust Acts is again a property of acts, which can be instantiated to a greater or lesser degree. It is plausible that you have a justice-based reason here to prevent Donald from committing more and larger injustices. This claim is admittedly more controversial than the claim made above, that any agent has a reason to promote justice in her own actions. ${ }^{11}$ But on the face of it it is not clear why, if justice (considered independently from well-being) provides a reason for an agent to act in one way rather than another in the case of her own actions, it should not provide some such reason

10 Also see Markosian's 2009 defense of Rossian minimalism, according to which "[a]n act is morally right iff it minimizes prima facie duty violations by its agent" (p. 7).

11 Indeed, some have argued that you do not have reason to prevent others from acting wrongly, on top of the reason you do have to prevent the bad effects of their wrongdoing (e.g., McMahan 2002, pp. 239-240; Scanlon 1998, p. 83; Frick 2016, pp. 258-9). 
in the case of the actions of others that the agent can influence. As David Wiggins says, in enlarging upon Justinian's conception of the virtue of justice: "[J] ustness ... comprises not only a certain kind of conscientiousness in acts of one's own but also a concern for that which just acts are carried out for, and a measure of preoccupation too with the doings of other agents."12

In Unjust Institutions, the kinds of injustice in question can be understood not only as properties of the actions of those involved, but as properties of institutions, of the basic structures of societies, or of societies themselves. Again it seems plausible to claim that one can promote justice in institutions by ensuring that those institutions are more just, or less unjust, than they would otherwise be.

It is fairly uncontroversial among those who accept justice-based reasons that you have reason to promote the justice of your nation or society, or of their institutions. It is more controversial whether you have justice-based reasons to promote the justice of other nations' or societies' institutions. However, some argue that, in virtue of your role in your society, and your society's doings, you do have justice-based reasons to promote the justice of other nations' institutions. ${ }^{13}$ Some non-cosmopolitans appear to believe that you have justice-based reasons to promote the justice of societies other than your own. ${ }^{14}$ Other theorists argue for a cosmopolitan picture according to which, morally, we all belong essentially to the same society, and so the distinction drawn between your society and others cannot carry much, if any, moral weight. ${ }^{15}$ It is worth noting here that structurally similar positions can be constructed as far as altruism or beneficence are concerned. For example, many believe that we have special obligations to assist our fellow citizens. But again it is important to recognize that this belief is consistent with accepting an impartial principle of beneficence which may in certain cases have greater practical weight than the partial principle (for example, when the benefit one can provide to fellow citizens is significantly smaller than that to non-citizens).

In Unjust Distributions, injustice can be seen as a property of a state of affairs or outcome. This property is again a matter of degree, and so one form of promoting justice lies in bringing it about that this property is less instantiated in the world than it would otherwise be. There is some controversy over

\footnotetext{
12 Wiggins (2004, p. 488).

13 For example, see Miller (2007) and Ashford (2018).

14 Rawls claims that what he calls the "fundamental natural duty" of justice (which presumably has pro tanto status) is "owed to persons generally" and includes the requirement "to further just arrangements not yet established" (1971/1999, p. 99).

Brock (2013).
} 
whether "purely distributive" reasons are genuinely justice-based reasons, ${ }^{16}$ but it is fairly uncontroversial that there are some such purely distributive reasons, whether they are classed as justice-based or not. ${ }^{17}$

These four typologies illustrate a range of ways in which one can promote justice. They also show how our claim that justice can be promoted is not equivalent to the controversial claim that justice should be understood entirely in terms of the impersonal value of states of affairs. While proponents of Effective Justice may consistently claim that justice - construed as a property of states of affairs - has impersonal value, they need not claim this. ${ }^{18}$

Perhaps the main philosophical hurdle to seeing the force of Impartial Justice and Maximizing Justice (and consequently, with the assumption of practical relevance, Effective Justice) is a failure to accept that justice can be promoted, or that it is the sort of thing the appropriate response to which can be promotion. Justice is often contrasted with things the appropriate response to which is promotion. ${ }^{19}$ For example, one might claim that justice requires that I treat you with respect, even if this has the result that respect for persons in general is not promoted. ${ }^{20}$ In fact, it would seem implausible if, while justice requires I treat you with respect, it were completely silent on how much reason I have to treat you with more or less disrespect. But even if justice truly does contrast with things the appropriate response to which is always promotion, this does not mean that justice is the sort of thing that it is never appropriate to promote. Even if there are spheres of justice in which the notion of promotion has no place, our four examples above show that there are several vitally important spheres in which justice can be promoted, and, plausibly, appropriately so.

It might be suggested that, if there are things other than justice to which promotion is never the appropriate response, an account of the appropriateness in question would jeopardize our claim that justice is, at least sometimes, to be promoted. Consider, for example, the beauty of some great painting, an appropriate response to which is admiration, or awe. We might reiterate our claim that promotion can be found a place here. You might, for example, be able to "promote" the continued existence of the painting and, hence, its beauty. But there is no need for us to insist on this. In our examples above, justice

\footnotetext{
16 Feldman (2016).

17 See Parfit (1991) and Temkin (2000) on equality and priority.

18 Proponents of Effective Altruism can also speak of impersonal value (value the bearer of which is not a sentient being) but may thereby be more open to a charge of doublecounting value if impersonal value is claimed to add value to that instantiated in the value of well-being (value the bearers of which are sentient beings).

19 There are exceptions. Consider, for example, Sen (1982) and Estlund (2016).

$20 \quad$ E.g., Pettit (1989 p. 121).
} 
can straightforwardly be promoted, and, plausibly, appropriately so. If there are things to which promotion is never the appropriate response (beauty, perhaps), so be it. Justice would then in a sense lie in between these things, and those to which promotion is always the appropriate response (pleasure, perhaps).

Note also that we are not claiming that there is no logical or conceptual space to deny our claims about the promotion of justice. A theorist of justice may wish to avoid all talk of promotion altogether, and even deny the comparative claims we have made about the justice and injustice of different courses of action. Consider, for example, our claim that, given a choice between greatly disrespecting another person and disrespecting them to a lesser degree, you should choose the latter option, and so promote justice. An opponent may suggest, in line with certain Stoic arguments, that both options are wrong, and neither is to be given any priority over the other.

Many people clearly accept something like Maximizing Altruism in at least certain spheres: they will buy their children the birthday presents that will please them most, for example. Further, many people accept that they have certain reasons to benefit those with whom they have weaker connections, such as others in their community. They may, for example, donate food to their local food bank. One upshot of the Effective Altruism movement has been an increase in the number of people who believe that they have a reason to promote well-being impartially, whether or not this is at the cost of any partial promotion of well-being in which they have been engaged. We might expect the same to happen with an Effective Justice movement, as people lift their eyes from the injustices closer or more salient to them and contemplate potentially much greater injustices at a distance.

\section{An Analogy among Disanalogies}

One might accept that justice can appropriately be promoted, but nonetheless be left wondering about the purported analogy between Effective Altruism and Effective Justice. What is so special about this analogy? After all, for any $\mathrm{X}$ that can appropriately be promoted in some impartial way, one can presumably defend an analogous combination of Impartial $X$ with Maximizing $X$ to yield the minimal philosophical underpinning of possible social movement Effective $X .^{21}$ There are at least two special features of Effective Altruism and

21 For any such movement to be justified, recall that certain assumptions about its effectiveness have to be true. 
Effective Justice that make the analogy between them particularly worthy of attention.

The first is that the sorts of reasons they concern are morally serious ones. Reasons to benefit others and reasons to promote justice seem the sorts of things that have a significant normative pull on all agents, regardless of their desires or projects, and that may, in the absence of defeaters, give rise to obligations. If there are reasons to promote things like beauty, they are at least not as plausibly morally serious in these ways. One may object that, if reasons to benefit others and promote justice are so morally serious that they defeasibly give rise to obligations, we will all too frequently be (defeasibly) obligated to put our money, time, and other resources toward these ends. But it is compatible with everything we say here that we have significant moral latitude to use what is rightfully ours as we please, which constrains the space within which even defeasible obligations to benefit others or promote justice can arise. ${ }^{22}$

The second special feature is that, for some things that can appropriately be promoted, there is arguably a sufficiency threshold beyond which there is no further reason to promote them, or where the reason for promotion diminishes out of proportion to the amount of the item in question. Consider, for example, species diversity, or human achievement. ${ }^{23}$ Perhaps ten thousand species is enough; maybe once one has won two Nobel prizes, the reason to accumulate more drops dramatically. There may be such things, but justice - at least in the spheres illustrated by our examples - is not one of them. The reason to promote justice does not diminish at any point, holding fixed the amount of justice promoted. If justice were promoted to such an extent that we found ourselves in a world of only very minor injustice, our reason to promote justice would be much weaker than it is now, but only because the promotable amounts would be much smaller. Similarly, the reason to benefit others does not diminish at any point, holding fixed the size of benefit conferred (and holding fixed features of beneficiaries that might modify the reason to benefit them, such as how well off or deserving they are). That there is such nondiminishing reason to benefit others and to promote justice importantly sets Effective Altruism and Effective Justice apart from other projects, with more easily exhaustible normative pulls.

We have argued that there is an important structural analogy between the minimal philosophical underpinnings of Effective Altruism on the one hand, and Effective Justice on the other. But we must recognize that the examples we

22 See Woollard (2015) (Ch. 7 and Ch. 8) and Woollard (2018) for discussion.

23 E.g., Lenman (2002) and Hurka (1983). 
have presented also illustrate certain readily apparent potential disanalogies between benefiting others and promoting justice. Here are six.

First, although both justice and beneficence, impartially construed, may be fully satisfiable (that is, there may be a world in which no further improvement in terms of either justice or beneficence is possible), promoting justice impartially can plausibly be thought of as a matter of reducing or preventing injustice, while promoting the good of others involves reducing harm and increasing benefit. But since decreasing injustice can be described as promoting justice, any disanalogy here does not seem to undermine the analogy we have defended.

Second, while there are several competing conceptions of well-being, there is more or less a single concept of it. On the other hand, there are multiple different concepts of justice each with its own cluster of competing conceptions. ${ }^{24}$ Perhaps Your Unjust Acts and Another's Unjust Acts are about one sense of justice, Unjust Institutions is about another, Unjust Distributions is about yet another, and these different senses of justice cannot be reduced to a single fundamental notion of justice. And perhaps these different senses of justice correspond to different bearers of justice (whereas acts, agents, institutions, and states of affairs are different types of bearers of justice, plausibly sentient individuals are the only type of bearer of well-being). Acts aimed at promoting justice almost always have mixed effects - improving justice in one respect but decreasing it in another. Giving money to charity, for example, may promote distributional justice at the price of promoting institutional injustice (by reinforcing capitalism, for instance). Would this promote justice all things considered? This would be an ill-formed question if distributional justice and institutional justice were fundamentally distinct senses of justice - there would be no single "covering consideration" of justice. ${ }^{25}$ On this picture, Maximizing Justice would likewise be ill-formed, and would need to be replaced with Maximizing Justice ${ }_{1}$, Maximizing Justice ${ }_{2}$, Maximizing Justice ${ }_{3}$, etc., one for each fundamentally distinct sense of justice there is. Thus, while Effective Altruism aims to promote well-being, there may be no single thing Effective Justice aims to promote. Indeed, there may be no single Effective Justice but a plurality one for each sense of justice. If this is correct, it would mark a significant disanalogy with Effective Altruism, but the structural analogy concerning reasons to promote and effectiveness would remain intact. A further related issue is whether there can be any intelligible comparisons of reasons to promote justice across these different senses or spheres of justice. Suppose an act has the

24 See Rawls (1971,1999, p. 5) for a seminal invocation of the concept/conception distinction.

25 See Chang (2015). 
mixed effect of improving justice in one sense but decreasing it in another. Even if there were no answer to the question of whether it promoted justice all things considered, perhaps we could nonetheless intelligibly ask what we have most reason to do all things considered (as it seems we can when moral reasons and prudential reasons pull in opposite directions). Our aim here is not to resolve these issues, but merely to raise them.

Third, it may be thought that the degree of disagreement over the correct theory of justice undermines the practical significance of Effective Justice (relative to some particular sense, or concept, of justice). But there is also significant disagreement over the correct theory of well-being: does some item advance one's well-being, for example, because it is pleasant, because it fulfills or would fulfill certain desires, or because it is good independently of any mental states? This disagreement at the explanatory level contrasts with much agreement at the substantive level. Almost all agree that losing one's sight through some painful disease is bad even if they disagree about what it is in virtue of which it is bad. The same contrast is found in the case of justice. Many agree, for example, that it is unjust of a billionaire not to pay his taxes. Many also agree that it is unjust that billions of people in the world do so much worse than others in terms of nutrition, education, and health. In both cases, there is significant disagreement about how to characterize these injustices at the theoretical level, i.e., about what makes the act or state of affairs in question unjust. $^{26}$

Fourth, proponents of Effective Justice may be concerned not - or not only - with the individuals who suffer injustice in absolute terms, but with the relations between them, such as inequality, and this may well turn out to be yet another disanalogy between Effective Justice and Effective Altruism. But again proportionality comes into play in a way that can render promotion appropriate: acts and institutions can treat people more or less unequally, states of affairs can contain more or less inequality. ${ }^{27}$ The corresponding reasons to promote justice vary in strength accordingly.

26 Our examples and claims here have tended to presuppose broadly liberal conceptions of justice, but what about people who accept racist, sexist, or homophobic conceptions of justice? Are we claiming that they have most reason, or a duty, to promote justice as they conceive of it? Note that the same problem arises for Effective Altruism, as some people advocate morally objectionable conceptions of well-being. Indeed this is nothing more than the old problem of whether someone who advocates acting virtuously is recommending that agents follow their consciences even when their moral views are false. Given the generality of that problem in ethics, we shall not seek to provide a solution in this paper.

27 See Temkin (1993) and Kagan (2014). 
Fifth, Effective Justice may be backward-looking in a respect that Effective Altruism is not. Altruism is usually understood as forward-looking in that it is concerned with enabling others to do better in the future than they might have done. The very idea of promotion is in itself forward-looking, but promoting justice may well indispensably involve taking into account past wrongs including those in which we ourselves may be implicated - by individuals or groups, and seeking through compensation or other means to rectify them as far as possible, as well as to minimize such wrongs in the future.

Sixth, some have raised the concern that, insofar as the philosophical underpinning of Effective Altruism is concerned solely with how you can most benefit others, it tacitly assumes an overly narrow form of moral individualism according to which, as Amia Srinivasan puts it, "the individual, not the community, class or state, is the proper object of moral theorizing." ${ }^{28}$ One might claim that this concern is even more pressing in the context of promoting justice, particularly that of communities, states, institutions, etc. To meet this concern, the underpinnings of both Effective Altruism and Effective Justice alike can be given a collectivist construal, so that they respectively pertain to the reasons we together have to benefit others and promote justice. ${ }^{29}$ However, there remains a potentially major complication concerning harmony between the individual and collective levels that arises in connection with the accumulation of justice over multiple separate instances of promoting (in)justice. Suppose, for example, that act (inflicting a harm of -10 on child A to achieve a benefit of +20 for child B) promotes injustice, act2 (inflicting a harm of -10 on child B to achieve a benefit of +20 for child A) promotes injustice, but [actı \& act2] promotes justice. Such non-accumulation of injustice over these individual acts could threaten the harmony between the individual and collective levels of Effective Justice (with the collective level favoring acts the individual level forbids or vice versa). On the other hand, insofar as well-being accumulates over multiple separate instances of promoting well-being, the analogous challenge could not arise for Effective Altruism. ${ }^{30}$ What should an Effective Justicist say? One option is to look for a way to harmonize the levels. For instance, in many cases, individual acts of promoting (in)justice are not parts of a mere collection, but are unified by some overarching plan, whether of a single agent or of a group of cooperating agents. Such unity could turn what would otherwise be individual acts of promoting injustice into individual acts of promoting

\footnotetext{
28 Srinivasan (2015). Also see Ashford (2018), Dietz (2019), and Collins (2019).

29 Further, we need not rule out the possibility that certain institutions have reasons to promote impartial justice analogous to those of individual agents.

3o For further discussion, see Clark and Pummer (2019) and Temkin (2019).
} 
justice. Such a solution is limited insofar as a collection of acts not so unified could nonetheless be said to promote justice or injustice. Another option for the Effective Justicist is to treat these putative cases of disharmony between collective and individual levels in something like the way they could treat cases of "mixed effects" (see above). We could distinguish between justice as a property of individual acts and justice as a property of a collection of acts, and argue that these refer to two fundamentally distinct senses of justice. We could then add that a collection of acts may well promote justice in the collective sense even if its members promote injustice in the individual sense. We could add also that injustice relative to some particular sense of justice does accumulate over separate instances of its promotion, perhaps depending on the sense in question. As before, our aim here is to recognize this sort of complication concerning Effective Justice rather than resolve it. Even if issues of levels and the accumulation of justice give rise to further disanalogies between Effective Justice and Effective Altruism, the key structural analogy concerning reasons to promote and effectiveness would remain intact.

None of the above disanalogies seem to undermine the crucial structural analogy between the underpinnings of Effective Altruism and Effective Justice. And together with minimally plausible claims about what justice consists in, as well as plausible empirical claims, Effective Justice would have a variety of practical implications. Imagine, for example, that you have made the decision to promote justice in education, and have $\$ 60,000$ to spend. You might use this to pay tuition fees at an élite university for a relatively poor American student who might otherwise be deterred from accepting a place; or you might donate the money to Oxfam, so they could build several schools facilitating access to education for hundreds of girls in the developing world. ${ }^{31}$ All other things are equal. The Effective Justicist will argue that, between these two alternatives and as far as justice is concerned, you have more reason to donate to Oxfam. Or consider gender inequality. Suppose you could donate to Fawcett, which campaigns for equality of pay between individuals in the U.K. (who are well off by global standards), ${ }^{32}$ or instead to an overseas charity such as Living Goods, which will, for $\$ 1,500$, help a woman who is disadvantaged by global

31 https://www.thelifeyoucansave.org/where-to-donate/oxfam.

32 http://www.fawcettsociety.org.uk/. 
standards to obtain a career as a Community Health Provider in Uganda. ${ }^{33}$ These examples should not be taken to suggest that Effective Justice is merely a matter of donating. Remember that one can promote justice in one's own acts (and hence character), and so it may be that Effective Justicists will decide to live in certain ways that involve focusing on engaged political action rather than donation to charities. Effective Justice, like Effective Altruism, should be seen as "means neutral," and not as committed to any particular means to its end.

On many plausible conceptions of well-being and of justice, and given plausible empirical claims, promoting more well-being by helping the world's extremely poor people will reliably coincide with promoting more justice, and it is accordingly likely that particular global poverty fighting charities ranked as promoting the most well-being would also be ranked as promoting the most justice. ${ }^{34}$ Even if there is not perfect convergence, it is still very plausible that the activities and charities favored by Effective Justice will reliably promote $a$ lot of well-being, as well as justice (relative to some particular sense of justice). There is thus an Effective Altruist case for Effective Justice. ${ }^{35}$

Many are motivated to give money and time out of a concern for justice rather than beneficence. ${ }^{36}$ Indeed, grassroots movements for social justice are plentiful. Just as Effective Altruism has had a wide transformative effect on beneficence-focused philanthropy, volunteerism, activism, and career selection, we believe that Effective Justice could have a similar effect on analogous justice-focused activities. We do not claim that the minimal philosophical views underpinning Effective Altruism and Effective Justice would be sufficient on their own to guide action. For this they would have to be combined with further claims, some of them empirical and some of them philosophical

33 https://www.thelifeyoucansave.org/Where-to-Donate/Living-Goods.

34 If one accepts a version of Effective Altruism which identifies reducing non-human animal suffering or reducing existential risks as the highest priority, there may be less overlap between activities and charities most favored by Effective Altruism and those most favored by Effective Justice (it would depend in part on the extent to which animals and future individuals are within the scope of justice as well as beneficence).

35 In addition, considerations of moral trade (Ord 2015) as well as moral uncertainty (Sepielli 2013; MacAskill and Ord 2018; Rosenthal 2018) may well strengthen the Effective Altruist case for Effective Justice.

36 Bekkers and Wiepking (2011). It may be that a greater proportion of those moved by justice will think that they have a duty to give or volunteer (and not that they are doing what is kind but "beyond the call of duty"), but plenty moved by beneficence think this too, including some Effective Altruists. 
(including claims about what well-being or justice consists in, and about the relative strength of competing reasons). But, at least when combined with some generally decent background beliefs and dispositions, we suspect that an appreciation of these minimal views will indeed help guide action.

\section{Acknowledgements}

We would like to thank the following for comments on and discussion of earlier drafts of this paper: Elizabeth Ashford, Elianna Fetterolf, Johann Frick, Iason Gabriel, Hilary Greaves, Cinara Nahra, Andrew Reisner, Andreas-Johann Sorger, David Wiggins, and two anonymous referees for this journal; and audiences at Trinity College Dublin, the Federal University of Santa Catarina, Florianópolis, the University of Glasgow, Karslruhe Institute of Technology, the University of Vita-Salute San Raffaele, Milan, the University of St Andrews, and the University of Oxford.

\section{References}

Ashford, Elizabeth. 2018. "Severe Poverty as an Unjust Emergency." In Paul Woodruff (ed.), The Ethics of Giving, pp. 103-148. Oxford: Oxford University Press.

Bekkers, René, and Wiepking, Pamala. 2011. "A Literature Review of Empirical Studies of Philanthropy: Eight Mechanisms That Drive Charitable Giving." Nonprofit and Voluntary Sector Quarterly 40: 924-973.

Brock, Gillian (ed.). 2013. Cosmopolitanism versus Non-Cosmopolitanism: Critiques, Defenses, and Reconceptualizations. Oxford: Oxford University Press.

Chang, Ruth. 2015. "Value Incomparability and Incommensurability." In Oxford Handbook of Value Theory, eds. Iwao Hirose and Jonas Olson. Oxford: Oxford University Press, pp. 205-24.

Clark, Matthew, and Pummer, Theron. 2019. "Each-We Dilemmas and Effective Altruism." Journal of Practical Ethics 7(1): 24-32.

Collins, Stephanie. 2019. "Beyond Individualism." In Effective Altruism: Philosophical Issues, eds. Hilary Greaves and Theron Pummer. Oxford: Oxford University Press.

Dietz, Alexander. 2019. "Effective Altruism and Collective Obligations." Utilitas 31(1): 106-115.

Estlund, David. 2016. "Just and Juster." Oxford Studies in Political Philosophy 2: 9-32.

Feldman, Fred. 2016. Distributive Justice: Getting What We Deserve From Our Country. Oxford: Oxford University Press. 
Foot, Philippa. 1983. "Utilitarianism and the Virtues." Proceedings and Addresses of the American Philosophical Association 57(1983): 273-283.

Fraser, Giles. 2017. "It's Called Effective Altruism-But is it Really the Best Way to Do Good?" The Guardian: <https://www.theguardian.com/money/belief/2017/nov/23/ its-called-effective-altruism-but-is-it-really-the-best-way-to-do-good $>$.

Frick, Johann. 2016. "What We Owe to Hypocrites: Contractualism and the SpeakerRelativity of Justification." Philosophy \& Public Affairs 44(4): 223-265.

Gray, John. 2015. "How \& How Not to Be Good." The New York Review of Books: <http:// www.nybooks.com/articles/2015/05/21/how-and-how-not-to-be-good/>.

Hurka, Thomas. 1983. "Value and Population Size." Ethics 93(3): 496-507.

Kagan, Shelly. 2014. The Geometry of Desert. New York: Oxford University Press.

Krishna, Nakul. 2016. "Add Your Own Egg." The Point: <http://thepointmag.com/2016/ examined-life/add-your-own-egg>.

Lenman, James. 2002. “On Becoming Extinct." Pacific Philosophical Quarterly 83(3): $5^{6-69 .}$

MacAskill, William. 2015. Doing Good Better: Effective Altruism and a Radical New Way to Make a Difference. London: Faber \& Faber.

MacAskill, William. 2019. "The Definition of Effective Altruism." In Effective Altruism: Philosophical Issues, eds. Hilary Greaves and Theron Pummer. Oxford: Oxford University Press.

MacAskill, William and Ord, Toby. 2018. "Why Maximize Expected Choice-Worthiness?" Noûs (online version, doi: 10.1111/nous.12264).

Markosian, Ned. 2009. "Rossian Minimalism." Journal of Ethics and Social Philosophy 4(1): 1-16.

McMahan, Jeff. 2002. The Ethics of Killing. New York: Oxford University Press.

Miller, David. 2007. National Responsibility and Global Justice. Oxford: Oxford University Press.

Ord, Toby. 2013. "The Moral Imperative towards Cost-Effectiveness in Global Health." Centre for Global Development: <www.cgdev.org/content/publications/detail/ 1427016>.

Ord, Toby. 2015. "Moral Trade." Ethics 126: 118-138.

Parfit, Derek. 1991. “Equality or Priority?” Lindley Lecture, University of Kansas.

Pettit, Philip. 1989. "Consequentialism and Respect for Persons." Ethics 100: 116-126.

Rawls, John. 1971/1999. A Theory of Justice, revised ed. Cambridge: Harvard University Press.

Rosenthal, Chelsea. 2018. "Why Desperate Times (But Only Desperate Times) Call for Consequentialism." Oxford Studies in Normative Ethics Vol. 8, ed. Mark Timmons.

Ross, W.D. 1930/2002. The Right and the Good. Oxford: Clarendon Press.

Ross, W.D. 1939. The Foundations of Ethics. Oxford: Clarendon Press.

Scanlon, T.M. 1998. What We Owe to Each Other. Cambridge: Harvard University Press. 
Sen, Amartya. 1982. "Rights and Agency." Philosophy and Public Affairs 11(1): 3-39.

Sepielli, Andrew. 2013. "What to Do When You Don't Know What to Do When You Don't Know What to." Noûs 48(3): 521-544.

Singer, Peter. 2015. The Most Good You Can Do: How Effective Altruism Is Changing Ideas about Living Ethically. London: Yale University Press.

Srinivasan, Amia. 2015. "Stop the Robot Apocalypse." London Review of Books Vol. 37 No.18: <http://www.lrb.co.uk/v37/n18/amia-srinivasan/stop-the-robot-apocalypse>.

Temkin, Larry. 2000. "Equality, Priority, and the Levelling-Down Objection." In Matthew Clayton \& Andrew Williams (eds.), The Ideal of Equality. Macmillan: 126-61.

Temkin, Larry. 2019. "Being Good in a World of Need: Some Empirical Worries and an Uncomfortable Philosophical Possibility." Journal of Practical Ethics 7(1): 1-24.

Thomson, Judith Jarvis. 2008. Normativity. Open Court.

Tumber, Catherine. 2015. "The Logic of Effective Altruism." Boston Review: $<$ https://bos tonreview.net/forum/logic-effective-altruism/catherine-tumber-response-effective -altruism>.

Wiggins, David. 2004. “Non-Aristotelian Reflections on Justice." Mind 113(451): 477-512. Woollard, Fiona. 2015. Doing and Allowing Harm. Oxford: Oxford University Press.

Woollard, Fiona. 2018. "Motherhood and Mistakes about Defeasible Duties to Benefit." Philosophy and Phenomenological Research 97(1): 126-149. 